\title{
Relationship between folate concentration and expression of folate-associated genes in tissue and plasma after intraoperative administration of leucovorin in patients with colorectal cancer
}

\author{
Helena Taflin ${ }^{1}$ D $\cdot$ Elisabeth Odin ${ }^{1} \cdot$ Kristoffer Derwinger $^{1} \cdot$ Göran Carlsson $^{1} \cdot$ Bengt Gustavsson $^{1}$. \\ Yvonne Wettergren ${ }^{1}$
}

Received: 3 April 2018 / Accepted: 24 September 2018 / Published online: 29 September 2018

(c) The Author(s) 2018

\begin{abstract}
Purpose The aim of study was to investigate the relationship between folate concentration and expression of folate-associated genes in tumour, mucosa and plasma of patients with colorectal cancer, after intraoperative administration of bolus leucovorin (LV).

Methods Eighty patients were randomized into four groups to receive $0,60,200$, or $500 \mathrm{mg} / \mathrm{m}^{2} \mathrm{LV}$, respectively. Tissue and plasma folate concentrations were assessed by LC-MS/MS. Gene expression of ABCC3/MRP3, FPGS, GGH, MTHFD1L, SLC46A1/PCFT, and SLC19A1/RFC-1 was determined using quantitative PCR.

Results The folate concentration in tumour increased with increasing dosage of LV. Half of the patients treated with $60 \mathrm{mg} /$ $\mathrm{m}^{2}$ did not reach a level above the levels of untreated patients. A significant correlation between folate concentration in tumour and mucosa was found in untreated patients, and in the group treated with $60 \mathrm{mg} / \mathrm{m}^{2} \mathrm{LV}$. The 5-MTHF/LV ratio correlated negatively with folate concentration in mucosa, whereas a positive correlation was found in tumour of patients who received 200 or $500 \mathrm{mg} / \mathrm{m}^{2} \mathrm{LV}$. A positive correlation was found between folate concentration and expression of all genes, except MTHFD1L, in patients who received LV. There was a negative correlation between 5-MTHF concentration in plasma of untreated patients and expression of GGH and SLC46A1/PCFT in tumour.

Conclusions The results indicate the possibility of using the individual plasma 5-MTHF/LV ratio after LV injection as a surrogate marker for tissue folate concentration. Expression of several folate-associated genes is associated with folate concentration in tissue and plasma and may become useful when predicting response to LV treatment.
\end{abstract}

Keywords Folate $\cdot$ Colorectal cancer $\cdot$ Gene expression $\cdot$ PCFT $\cdot$ RFC-1

\section{Introduction}

Colorectal cancer (CRC) is a major cause of cancer death worldwide $[1,2]$. The median overall survival from metastatic disease is now reaching almost 30 months in clinical

Electronic supplementary material The online version of this article (https://doi.org/10.1007/s00280-018-3690-9) contains supplementary material, which is available to authorized users.

Helena Taflin

helena.taflin@vgregion.se

1 Department of Surgery, Institute of Clinical Sciences, Sahlgrenska University Hospital/Östra, Sahlgrenska Academy at University of Gothenburg, 41685 Gothenburg, Sweden trials, which is due to development of new biological agents in addition an increasing number of patients undergoing surgical resection of localized metastatic disease. A more strategic approach to the delivery of systemic therapy and an expansion in the use of ablative techniques may also contribute to improvement of survival [3]. However, in the clinical setting, the overall survival can be expected to be lower [4].

The fundament in the treatment of CRC is surgery. However, after primary surgery, treatment with chemotherapy is recommended for advanced tumour stages [5]. The drug 5-fluorouracil (5-FU) is used as a cornerstone of chemotherapy treatment, in the adjuvant, as well as in the palliative setting for CRC [6-8]. This drug is an analogue of uracil, in which the hydrogen at position 5 is replaced by fluorine. 5-FU enters the cell in the same way as uracil and is then converted in several steps intracellularly 
to the final active metabolite 5-fluoro-2'-deoxyuridine monophosphate (FdUMP). The enzyme thymidylate synthase (TS; EC 2.1.1.45), catalyses the reductive methylation of deoxyuridine monophosphate (dUMP) to deoxythymidine monophosphate (dTMP) using 5,10-methylenetetrahydrofolate $(5,10$-MeTHF) as the methyl-group donor. Subsequently, dTMP is further phosphorylated to become deoxythymidine triphosphate (dTTP), which is an essential nucleotide needed in DNA synthesis and repair. When FdUMP is replacing dUMP, the TS enzyme is inhibited thereby blocking the conversion of dUMP to dTMP. Since this conversion is the only way for de novo formation of dTMP, the blockage will impair both DNA synthesis and repair $[8,9]$. The greatest impact will be on cells having a high proliferation rate, such as cancer cells [10].

The response rate of colorectal tumours to 5-FU monotherapy is only around $10 \%$. By adding a reduced folate, the tumour response rate can be improved to $21 \%$, as has been shown in a meta-analysis [11]. In clinical practice, patients treated with 5-FU will receive the reduced folate leucovorin $(\mathrm{LV})$ in the form of a stable calcium salt of 5-formyltetrahydrofolic acid (calcium folinate). After injection, LV is transported to the liver where it is mainly metabolized to 5-methyltetrahydrofolate (5-MTHF). This metabolite is then transported to the blood stream to reach other tissues. The maximum plasma concentration of 5-MTHF is reached 30 min after i.v. administration [12]. LV is eliminated by 80-90\% through the kidneys.

The Nordic FLV therapy, which is a regime of bolus 5-FU and LV that was introduced in the 1990s, is still the cornerstone of both adjuvant and palliative treatments for CRC in Nordic countries [13]. Although the Nordic FLV is a well-established regimen, the evidence for a beneficial effect of the LV dosage and administration used is rather limited. Different regimens used in clinical practice worldwide apply LV concentrations that range from 20 to $500 \mathrm{mg} / \mathrm{m}^{2}$ and are often empirically evolved [14].

Leucovorin needs to be converted in several steps into the active substance 5,10-MeTHF. This metabolite is polyglutamated by the enzyme folylpolyglutamate synthase (FPGS), which increases its cellular retention. 5,10-MeTHF stabilizes the ternary complex between TS and FdUMP, hence, leading to inhibition of the formation of dTMP from dUMP [15]. In order to get a complete inhibition of TS, the active metabolite 5,10-MeTHF must be in excess. Then, a maximal formation of the ternary complex consisting of TS, FdUMP, and 5,10-MeTHF can be achieved [16, 17].

A recent article published by our group presented data showing a large inter-individual variation of tissue folate concentration in patients with CRC after supplementation with LV at standardized dosage [18]. The concentrations of tetrahydrofolate (THF), 5,10-MeTHF and 5-MTHF in tumour and mucosa were assessed by liquid chromatography electrospray ionization tandem mass spectrometry (LC-MS/ MS). The results showed that the 5,10-MeTHF concentration in tumours of many patients given the standardized dose of $L V$, i.e. $60 \mathrm{mg} / \mathrm{m}^{2}$, did not exceed the values of an untreated control group. Rectal cancer patients in particular required high doses of $\mathrm{LV}$ to reach a tumour tissue concentration of 5,10-MeTHF above baseline. Similar results have been described by Houghton et al. [19].

In the present study, we hypothesize that folate administration has an effect on gene expression that may be clinically relevant. The folate concentration in matching tumour and mucosa tissue obtained from patients with CRC were determined and compared with the concentration in plasma after treatment with increasing doses of LV. The impact of the folate concentration in tissue and plasma on gene expression of six folate pathway genes was analysed.

\section{Patients and methods}

Eighty patients scheduled for a colorectal resection with a cancer indication were enrolled in the study between January 2011 and January 2012. All patients gave their written informed consent. The pre-operative exclusion criteria were patient inability to understand the study information or inability to provide true informed consent. There were no other exclusion criteria. The patients were pre-operatively randomized into four groups; the first served as control group and received no LV. Groups 2, 3, and 4 received 60, 200, and $500 \mathrm{mg} / \mathrm{m}^{2} \mathrm{LV}$, respectively, administered intravenously as a bolus injection at the initiation of general anaesthesia. The $\mathrm{LV}$ was manufactured in the form of calcium folinate (RSLV) supported by Teva Sweden AB, Helsingborg, Sweden. The surgeon was blinded to the dosage given and all patients were otherwise treated in accordance with normal routines and guidelines.

During surgery, at the time of removal of the surgical specimen, a research nurse collected fresh tissue samples from both tumour and macroscopically normal-appearing mucosa located $10 \mathrm{~cm}$ from the tumour. The biopsies were snap-frozen in liquid nitrogen and stored at $-80^{\circ} \mathrm{C}$ until used. Clinical and pathology data regarding diagnosis, tumour differentiation and stage, and pre-operative treatment regimen were retrieved to assess the different groups and enable a better understanding of the factors that might influence treatment responses.

\section{Determination of plasma folate}

Blood samples were obtained from all patients. The samples were collected at 0,10 , and $30 \mathrm{~min}$. in EDTA vacutainers and immediately centrifuged $\left(4{ }^{\circ} \mathrm{C}, 2000 \mathrm{~g}, 10 \mathrm{~min}\right)$. The plasma was stored at $-80{ }^{\circ} \mathrm{C}$ until LC-MS/MS analysis. 
To $1 \mathrm{ml}$ of $[(0,2 \%$ formic acid in acetonitrile): Methanol (9:1)], $200 \mu \mathrm{l}$ plasma was added, and mixed well for $10 \mathrm{~min}$. Aminoacetophenone was used as internal standard. Stock aminoacetophenone solution $(0.1 \mathrm{mM})$ was stored at $-80{ }^{\circ} \mathrm{C}$ until use. After addition of $20 \mu \mathrm{l}$ internal standard and $30 \mu \mathrm{l}$ of water, the samples were centrifuged for $10 \mathrm{~min}$ at $21,500 \mathrm{~g}$. The supernatant was loaded on a $1 \mathrm{cc}$ Oasis PRIME HLB Cartridge and passed-through. The eluate was collected and evaporated to dryness and reconstituted with $300 \mu$ l Mobile phase A before analysis. A stock solution $(20 \mathrm{mM})$ of LV and 5-MTHF was dissolved in extraction buffer (50 mM phosphate buffer ( $\mathrm{pH} 7.0), 1 \%$ sodium ascorbate and $0.1 \% \beta$-mercaptopropanol) and stored at $-80{ }^{\circ} \mathrm{C}$ until use. The folate solution was serially diluted in extraction buffer to prepare the calibration curves. A blank plasma sample was used to dilute the standard samples. A mixture of standards and internal standard was extracted as described for the samples. Calibration standards containing ten different concentrations for LV and 5-MTHF were used. The quality $(\mathrm{Q})$ controls low, medium and high were prepared in plasma, and extracted as described for the samples. The extracted ions following MRM transitions were monitored at $m / z 460 \rightarrow 313$ for 5-MTHF, $m / z 474 \rightarrow 327$ for LV, and $136 \rightarrow 94$ for aminoacetophenone. The mean calibration curves for 5-MTHF $\left(y=0.1883 x+0.0187, R^{2}\right)$ and LV $\left(y=0.0752 x+0.1836, R^{2}=0.9973\right)$ were measured on different days $(n=9)$. Variability was determined by analysing plasma Q-sample $(n=7)$ at low, medium and high concentration and also between days $(n=9)$. The relative standard deviation (RSD) for 5-MTHF and LV ranged from 2 to $6.2 \%$ within the same day and the variability over 9 days ranged from 4.9 to $10.4 \%$. Sensitivity was assessed by evaluating the limit of detection (LOD) and limit of quantification (LOQ) for the method. The LOD and LOQ were defined as the lowest analyte concentration yielding a signal-to-noise $(\mathrm{S} / \mathrm{N})$ ratio of 3 and 10 , respectively. The LOD for 5-MTHF and LV was 0.3 and $1.6 \mathrm{pmol} / \mathrm{ml}$, respectively. The LOQ for 5-MTHF and LV was 0.9 was and $5.2 \mathrm{pmol} / \mathrm{ml}$, respectively.

\section{Determination of tissue folate}

LC-MS/MS was used to measure concentrations of the folate derivatives 5,10-MeTHF, THF, and 5-MTHF, expressed as $\mathrm{pmol} / \mathrm{g}$ wet-weight (pmol/gww), in tumour tissue and adjacent mucosa [20]. Raltitrexed was used as an internal standard. The sum of the 5,10-MeTHF, THF, and 5-MTHF concentrations was used as a measure of folates in the tissue. The extracted ions following MRM transitions were monitored at $m / z, 446 \rightarrow 299$ for THF, $m / z 458 \rightarrow 311$ for 5,10 -MeTHF, $m / z, 460 \rightarrow 313$ for 5 -MTHF, and $m / z, 459$ $\rightarrow 312$ for raltitrexed.

On the day of sample analysis, extraction buffer was prepared containing $50 \mathrm{mM}$ phosphate buffer, $\mathrm{pH}$ 7.0, $1 \%$ ascorbate, and $0.1 \% \beta$-mercaptopropanol. The tissue was weighed and placed in an Eppendorf vial and a $10 \times$ volume of extraction buffer was added. Homogenization was performed using a TissueLyser (two disruption steps at $25 \mathrm{~Hz}$ for $2.5 \mathrm{~min}$ ). After a deconjugation step, protein precipitation, centrifugation, and ultrafiltration $(30 \mathrm{~min}$ at $21,500 \times \mathrm{g}$ at $20{ }^{\circ} \mathrm{C}$ ) were performed. The solution at the bottom of the test tube was used for LC-MS/MS analysis. The relative standard deviation (RSD) ranged from 2 to $7 \%$ for all analyses, and the variability over 4 days ranged from 3 to $14 \%$. The accuracy of the method was determined by estimating the recovery by adding known amounts of the standard to a sample. The average recoveries were 98,87 , and 93\% for THF, 5,10-MeTHF, and 5-MTHF, respectively. The LOD for 5,10-MeTHF, THF and 5-MTHF was 2.1, 1.2 and $0.3 \mathrm{pmol} / \mathrm{g}_{\mathrm{ww}}$, respectively. The LOQ for 5,10-MeTHF, THF and 5-MTHF was 4.0, 7.0 and $0.9 \mathrm{pmol} / \mathrm{g}_{\mathrm{ww}}$, respectively. Standard curves for 5,10-MeTHF, THF, and 5-MTHF in tissue have been presented in a previous paper [20].

The LC-MS/MS analyses were performed on a Waters 2795 LC separation module coupled to a Waters Micromass Quattro Triple-Quadrupole MS system with an electrospray ionization (ESI) source. Folates were detected and quantified using positive electrospray. The separation of folates was performed using an Atlantis dC18 $3 \mu \mathrm{m}, 2.1 \times 100 \mathrm{~mm}$ column (Waters) together with the guard column Atlantis $\mathrm{dC} 18,3 \mu \mathrm{m}, 2.1 \times 10 \mathrm{~mm}$. The mobile phase consisting of eluent A $(0.1 \%$ of acetic acid in water) and eluent B $(0.1 \%$ acetic acid in acetonitrile) was used. Calibration graphs were constructed by plotting the peak area ratio of each compound to internal standards against concentration. The standards and samples were processed using the QuanLynx quantitative processing tool in MassLynx (Waters Corp., Milford, MA, USA). A more detailed description of the folate assay development has been published previously [20].

\section{Preparation of RNA and CDNA}

Total RNA was isolated from 10 to $30 \mathrm{mg}$ fresh-frozen tissue using the High Pure RNA Tissue Kit (\#12033674001, Roche Diagnostics Scandinavia $\mathrm{AB}$ ) according to the manufacturer's instructions. cDNA was synthesized using the High Capacity cDNA Reverse Transcription Kit (Applied Biosystems) and run on Gene Amp PCR System 9600 (Perkin Elmer). To optimize each run, the expression level of $\beta$-actin was determined in each sample. A second RNA extraction and cDNA synthesis was performed if the concentration was considered to be suboptimal.

\section{Real-time quantitative PCR}

Based on recent studies [19], five target genes with putative impact on LV metabolism were chosen for analysis 
(Supplementary Table 1). These genes are involved in folate transport (ABCC3, SLC19A1/RFC-1 and SLC46A1/PCFT), folate polyglutamation (FPGS and GGH) or folate metabolism (MTHFD1L). The relative gene expression was quantified in tumours and mucosa using real-time quantitative PCR (qPCR). TaqMan Gene Expression Assays (Life Technologies, Stockholm, Sweden) were ordered for each gene from Applied Biosystems at http://www.appliedbiosystems.com. The qPCR was set up in triplicates in 384-well plates using a Nanodrop II (GC Biotech) and was carried out in $5 \mu \mathrm{l}$ reactions with $1 \times \mathrm{TaqMan}^{\circledR}$ Gene Expression Mastermix (Applied Biosystems), $1 \times$ gene-specific TaqMan assay (Applied Biosystems), and $1 \mu \mathrm{lDNA}$. The qPCR was run on a QuantStudioTM 12K Flex Real-Time PCR System (Life Technologies, Stockholm, Sweden) according to a standard protocol. The thresholds and baselines were set manually using the sequence detection systems software (SDS), version 2.4 (Applied Biosystems), and cycle threshold $\left(C_{\mathrm{t}}\right)$ values were extracted. Variations between runs were compensated for by normalization against a control sample. There was a linear correlation between the two house-keeping genes ACTB and GAPDH. All $C_{\mathrm{t}}$ values were normalized to a mean value representing both of these genes in order to keep variance to the minimum.

\section{Statistical analyses}

The JMP 11.0/SAS software (SAS Institute Inc. Cary, NC, USA) was used for the statistical analyses. All gene expression calculations were performed using the $\Delta \Delta C_{\mathrm{t}}$ method. As the values of the gene expression and folate concentrations were not normally distributed, they were transformed to be logarithmic. Differences between groups were calculated using the Kruskal-Wallis' test, the Pearson's Chisquare test, or the matched-pair analyses (Wilcoxon signed rank test) and data were presented as median and ranges. Values of $p \leq 0.05$ were considered significant. No corrections for multiple testing were done.

\section{Results}

Three patients were excluded from the study because routine pathology reports revealed a lack of adenocarcinoma tissue; two patients had an obstruction related to diverticulitis, one had a squamous epithelial cancer. Furthermore, during analysis of blood samples, it was discovered that one patient had received a LV dose that was not according to the protocol and, as a consequence, this patient was excluded from the study. Due to surgical complication with extensive bleeding during the operation, it was not possible to remove the tumour of one patient at the primary operation. This resulted in a time span between the LV injection and tissue collection of almost $30 \mathrm{~h}$. Due to the extended time, the tissue values of folates were not reliable and the patient was excluded from the study. Thus, in total, 75 patients were included. Based on clinical diagnosis, 38 patients had colon cancer and 34 had rectal cancer. Three patients had cancer in both rectum and colon synchronously. The median time (min-max) that passed from LV injection to tissue sampling was $170 \mathrm{~min}$ (65-285) for patients receiving $60 \mathrm{mg} / \mathrm{m}^{2}, 165 \mathrm{~min}(72-457)$ for patients receiving $200 \mathrm{mg} / \mathrm{m}^{2}$, and $163 \mathrm{~min}(65-555)$ for patients receiving $500 \mathrm{mg} / \mathrm{m}^{2}$. The variation was linked to the operating time, which differed depending on the type of surgical procedure. However, there was no significant difference in the time course from LV injection to tissue sampling between treatment groups $(p=0.91)$. The demographic, clinical and pathological data are shown in Table 1.

The ranges of the tissue folate concentration were very wide, reflecting a huge inter-individual variation (Table 2). The median folate concentration in both tumour and mucosa tissue increased with increasing dosage of LV (Fig. 1a; Table 2). As shown in Fig. 1a, about 50\% of patients who received $60 \mathrm{mg} / \mathrm{m}^{2}$ did not reach a folate concentration in tumours above the concentration found in untreated patients. There was a strong and significant correlation between the folate concentration in tumour and mucosa tissue of untreated patients, as well as in patients treated with $60 \mathrm{mg} / \mathrm{m}^{2} \mathrm{LV}$ (Fig. 1b), but no correlation was found in patients treated with 200 or $500 \mathrm{mg} / \mathrm{m}^{2} \mathrm{LV}$.

The median concentrations of LV and 5-MTHF in plasma of patients grouped by given LV dose are presented in Table 3. No correlation was found between LV and 5-MTHF in samples obtained from patients who received $60 \mathrm{mg} / \mathrm{m}^{2} \mathrm{LV}(r=0.36, p=0.13)$. However, there was a strong, positive, correlation between the LV and 5-MTHF concentration in plasma obtained from patients who received 200 or $500 \mathrm{mg} / \mathrm{m}^{2} \mathrm{LV}(r=0.60, p=0.0061$ and $r=0.76, p=0.0001$, respectively).

When the association between 5-MTHF concentration in plasma at baseline and folate concentration in mucosa was evaluated, a positive correlation was found $(r=0.5$, $p=0.035$ ). The maximum plasma concentration achieved for $\mathrm{LV}$ was found $10 \mathrm{~min}$. after LV injection whereas the highest 5-MTHF was found after $30 \mathrm{~min}$. Based on these values, the 5-MTHF/LV ratio was calculated for the patients of each group treated with LV (Supplementary Fig. 1). As shown, the ratio between 5-MTHF and LV decreased with higher dose of LV given and a great variation was seen between patients, especially in those who received $60 \mathrm{mg} / \mathrm{m}^{2}$. The $5-\mathrm{MTHF} / \mathrm{LV}$ ratio correlated negatively with folate concentration in mucosa $(r=-0.75$, $p=0.0009)$. In patients treated with 200 or $500 \mathrm{mg} / \mathrm{m}^{2}$, however, the ratio correlated positively with folate concentration in tumour tissue ( $r=0.51, p=0.031$ and $r=0.52$, $p=0.019$, respectively). 
Table 1 Clinicopathological characteristics of the patients with colorectal cancer subgrouped by leucovorin dose

\begin{tabular}{|c|c|c|c|c|c|}
\hline \multirow[t]{2}{*}{ Parameter } & \multirow[t]{2}{*}{ All patients } & \multicolumn{4}{|c|}{ Leucovorin dose } \\
\hline & & $0 \mathrm{mg} / \mathrm{m}^{2}$ & $60 \mathrm{mg} / \mathrm{m}^{2}$ & $200 \mathrm{mg} / \mathrm{m}^{2}$ & $500 \mathrm{mg} / \mathrm{m}^{2}$ \\
\hline Median age in years (range) & $72(37-89)$ & $73(67-81)$ & $66(42-87)$ & $70(37-89)$ & $75(37-87)$ \\
\hline \multicolumn{6}{|l|}{$\operatorname{Sex}(n)$} \\
\hline Men & 39 & 11 & 12 & 7 & 9 \\
\hline Women & 36 & 7 & 6 & 12 & 11 \\
\hline \multicolumn{6}{|l|}{ Tumour location $(n)$} \\
\hline Colon (right/left) & 38 & $10(7 / 3)$ & $10(5 / 5)$ & $8(7 / 2)$ & $10(7 / 4 / 1)$ \\
\hline Rectum & 34 & 7 & 8 & 10 & 9 \\
\hline Synchronous & 3 & 1 & 0 & 1 & 1 \\
\hline \multicolumn{6}{|l|}{ Tumour stage $(n)$} \\
\hline I & 4 & 0 & 0 & 1 & 3 \\
\hline II & 32 & 7 & 7 & 9 & 9 \\
\hline III & 33 & 9 & 9 & 8 & 7 \\
\hline IV & 6 & 1 & 1 & 2 & 2 \\
\hline \multicolumn{6}{|l|}{ Tumour differentiation $(n)$} \\
\hline Well & 1 & 1 & 0 & 0 & 0 \\
\hline Moderate & 50 & 14 & 13 & 11 & 12 \\
\hline Poor & 17 & 3 & 2 & 6 & 6 \\
\hline Mucinous & 7 & 0 & 3 & 2 & 2 \\
\hline \multicolumn{6}{|c|}{ Pre-operative radio- or chemotherapy $(n)$} \\
\hline Short-term RT $(5 \times 5 G)$ & 13 & 0 & 6 & 5 & 2 \\
\hline Long-term RT and CT & 3 & 0 & 1 & 1 & 1 \\
\hline
\end{tabular}

$R T$ radiotherapy, $C T$ chemotherapy
Gene expression was analysed in both tumour and mucosa tissues (Table 2). Similar to the folates, the variation in gene expression levels was very high. In untreated patients, the expression of GGH and MTHFD1L was significantly higher in tumour tissue compared to mucosa. After LV injection, a significantly higher gene expression level of GGH, MTHFD1L, SLC19A1/RFC-1, and FPGS was seen in tumour tissue compared to mucosa. However, this was not the case for ABCC3/MRP3 and SLC46A1/ PCFTPCFT, which had higher expression levels in mucosa compared to tumour.

The expression of each gene increased with increasing dose of LV in tumour tissue after adjustment for time passed after LV injection (Fig. 2). However, there was no difference in expression levels according to the LV dose in mucosa (data not shown). The association between folate concentration and expression of each analysed gene in tumour and mucosa was evaluated (Table 4). A significant, negative correlation was seen between folate concentration and GGH and MTHFD1L expression in mucosa of untreated patients, but no correlation was seen in the tumour. In contrast, a significant, positive correlation was found between folate concentration and expression of all genes, except MTHFD1L, in patients who received LV (Table 4). In mucosa, the folate concentration correlated positively with expression of SLC46A1/PCFT.
As shown in Table 5, there was a negative correlation between 5-MTHF concentration in plasma obtained from untreated patients and expression of GGH and SLC46A1/ PCFT in tumour tissue, but no correlation was seen for any of the other genes. In mucosa of untreated patients, the 5-MTHF concentration tended to correlate negatively with SLC46A1/PCFT.

\section{Discussion}

As previously stated, bolus treatment with $5-\mathrm{FU}$ is given in combination with $\mathrm{LV}$, which significantly enhances the therapeutic effect of 5-FU. FLV-treatment, both in the adjuvant and palliative setting, is usually combined with other chemotherapy drugs such as oxaliplatin or irinotecan, as well as specific antibodies. However, many patients do not respond to the chemotherapy, or will develop drug resistance during treatment. The inter-individual variation in treatment response may relate to differences in drug metabolism [21]. Although 5-FU-based treatment is a cornerstone in almost all CRC regimens, there is no clinically useful biochemical predictive marker that can be used to evaluate treatment effect.

As mentioned previously, LV has to be metabolized intracellularly to the active metabolite 5,10-MeTHF. The optimal 
Table 2 Comparison of median folate concentration and gene expressions levels in tumour and mucosa tissues of patients with CRC subgrouped by leucovorin dose

\begin{tabular}{|c|c|c|c|c|c|c|c|c|}
\hline & \multicolumn{8}{|l|}{ Leucovorin dose } \\
\hline & $\begin{array}{l}0 \mathrm{mg} / \mathrm{m}^{2} \\
\text { median (range) }\end{array}$ & $p^{\mathrm{a}}$ & $\begin{array}{l}60 \mathrm{mg} / \mathrm{m}^{2} \\
\text { median (range) }\end{array}$ & $p^{\mathrm{a}}$ & $\begin{array}{l}200 \mathrm{mg} / \mathrm{m}^{2} \\
\text { median (range) }\end{array}$ & $p^{\mathrm{a}}$ & $\begin{array}{l}500 \mathrm{mg} / \mathrm{m}^{2} \\
\text { median (range) }\end{array}$ & $p^{\mathrm{a}}$ \\
\hline \multicolumn{9}{|c|}{ Folate concentration ${ }^{\mathrm{b}}$} \\
\hline Tumour & 1009 (461-2256) & 0.12 & $3297(1341-4938)$ & 0.12 & $5526(4048-14,641)$ & 0.0079 & $8248(5824-13,086)$ & 0.13 \\
\hline Mucosa & $847(413-1591)$ & & $2519(1571-4670)$ & & $4576(2869-5607)$ & & $6382(4487-21,249)$ & \\
\hline \multicolumn{9}{|c|}{ ABCC3/MRP3 } \\
\hline Tumour & $1.7(0.15-5.1)$ & 0.056 & $0.90(0.19-3.3)$ & 0.0002 & $0.93(0.12-8.5)$ & 0.0056 & $1.8(0.38-9.0)$ & 0.083 \\
\hline Mucosa & $2.4(0.14-43)$ & & $2.8(0.26-15)$ & & $3.3(0.98-7.0)$ & & $3.3(0.80-12)$ & \\
\hline \multicolumn{9}{|l|}{ FPGS } \\
\hline Tumour & $5.3(1.1-25)$ & 0.25 & $5.3(1.8-30)$ & 0.0021 & $5.5(1.0-127)$ & 0.0056 & $14(1.2-150)$ & $<0.0001$ \\
\hline Mucosa & $3.6(0.56-318)$ & & $2.4(1.1-11)$ & & $3.1(0.53-29)$ & & $3.8(0.68-48)$ & \\
\hline \multicolumn{9}{|l|}{ GGH } \\
\hline Tumour & $7.6(0.35-33)$ & 0.021 & $4.6(1.3-22)$ & 0.0021 & $4.4(1.5-337)$ & 0.0003 & $8.4(0.41-292)$ & 0.0014 \\
\hline Mucosa & $1.9(0.11-49)$ & & $2.2(0.69-7.5)$ & & $1.7(0.37-6.6)$ & & $2.4(0.072-6.9)$ & \\
\hline \multicolumn{9}{|c|}{ MTHFD1L } \\
\hline Tumour & $1.7(0.32-9.6)$ & 0.0034 & $1.5(0.25-6.2)$ & 0.0008 & $2.3(0.33-71)$ & $<0.0001$ & $2.6(0.15-19)$ & $<0.0001$ \\
\hline Mucosa & $0.44(0.074-9.2)$ & & $0.46(0.094-7.2)$ & & $0.35(0.047-3.8)$ & & $0.41(0.059-5.6)$ & \\
\hline \multicolumn{9}{|c|}{ SLC19A1/RFC-1 } \\
\hline Tumour & $1.5(0.33-8.5)$ & 0.47 & $1.6(0.17-7.4)$ & 0.011 & $2.2(0.42-103)$ & 0.0001 & $4.4(0.43-54)$ & 0.0003 \\
\hline Mucosa & $0.9(0.28-11)$ & & $0.72(0.23-4.9)$ & & $0.86(0.17-6.3)$ & & $0.96(0.3-28)$ & \\
\hline \multicolumn{9}{|c|}{ SLC46A1/PCFT } \\
\hline Tumour & $0.88(0.02-6.0)$ & 0.13 & $0.40(0.062-2.7)$ & 0.034 & $0.46(0.08-26)$ & 0.77 & $1.57(0.09-40)$ & 0.45 \\
\hline Mucosa & $1.1(0.08-19)$ & & $0.65(0.23-11)$ & & $1.1(0.07-4.1)$ & & $1.7(0.12-8.3)$ & \\
\hline
\end{tabular}

${ }^{\mathrm{a}} p$ by Wilcoxon signed rank test

${ }^{\mathrm{b}} \mathrm{pmol} / \mathrm{mg}$

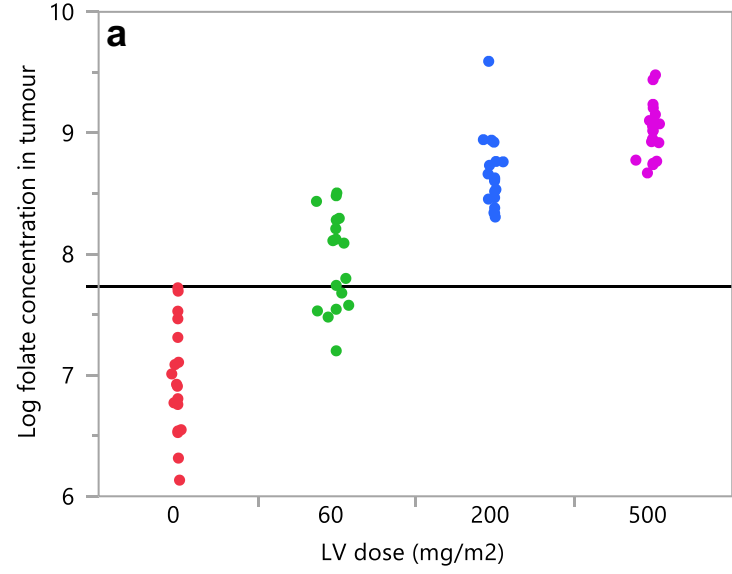

Fig. 1 a The folate concentration increased with increasing LV dosage in tumour tissue. The horizontal line marks the highest folate concentration found in untreated patients. b A significant correlation was seen between folate concentrations in tumour and mucosa of untreated patients (red dots, no LV, $r=0.63, p=0.0048$ ) and patients

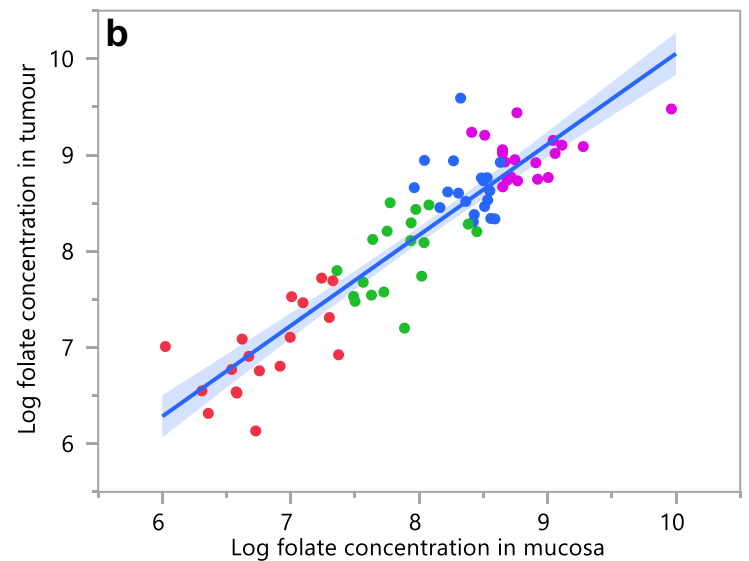

treated with $60 \mathrm{mg} / \mathrm{m}^{2} \mathrm{LV}$ (green dots, $r=0.57, p=0.011$ ), however, the correlation was not significant in patients treated with 200 (blue dots) or 500 (purple dots) $\mathrm{mg} / \mathrm{m}^{2} \mathrm{LV}$. The line of fit is shown with the confidence interval (blue-shaded area) 
Table 3 Leucovorin and 5-MTHF levels in plasma of patients with CRC sub-grouped by leucovorin dose

\begin{tabular}{cllll}
\hline & \multicolumn{2}{l}{ Leucovorin dose } & & \\
\cline { 2 - 5 } & $\begin{array}{l}0 \mathrm{mg} / \mathrm{m}^{2} \\
\text { median (range) }\end{array}$ & $\begin{array}{l}60 \mathrm{mg} / \mathrm{m}^{2} \\
\text { median (range) }\end{array}$ & $\begin{array}{l}200 \mathrm{mg} / \mathrm{m}^{2} \\
\text { median (range) }\end{array}$ & $\begin{array}{l}500 \mathrm{mg} / \mathrm{m}^{2} \\
\text { median (range) }\end{array}$ \\
\hline $\begin{array}{l}\text { Leucovorin }^{\mathrm{a}} \\
0 \mathrm{~min}\end{array}$ & 0 & 0 & 0 & 0 \\
$10 \mathrm{~min}$ & 0 & $69.2(25.8-194)$ & $152.1(84.3-299)$ & $368(94.4-918)$ \\
$30 \mathrm{~min}$ & 0 & $45.8(16.6-114)$ & $111(72.2-255)$ & $279.1(61.4-687)$ \\
$5-\mathrm{MTHF}$ & & & $13.4(1.23-46.9)$ & $6.07(0.34-43.8)$ \\
$0 \mathrm{~min}$ & $7.32(0.41-51.0)$ & $6.65(0.055-91.9)$ & $395(188-1102)$ & $705(146-1276)$ \\
$10 \mathrm{~min}$ & $5.98(0.4-44.3)$ & $240(81.3-412)$ & $1237(621-3601)$ & $1909(538-2914)$ \\
$30 \mathrm{~min}$ & $6.02(0.45-17.6)$ & $653(274-1157)$ & & \\
\hline${ }^{\mathrm{a}} \mathrm{nmol} / \mathrm{ml}$ & & & &
\end{tabular}

intracellular concentration of folates for effective TS inhibition is presently not known but is expected to depend on the individual TS activity as well as the activity of several folate-associated enzymes. In order to get a complete inhibition of the target enzyme TS, 5,10-MeTHF must be in excess. Consequently, a low 5,10-MeTHF concentration in the tumour tissue is associated with clinically impaired 5-FU activity. High doses of LV are needed to achieve a maximum formation of the ternary complex between TS, FdUMP, and $5,10-$ MeTHF. LV is a racemic mixture of the natural (S) and unnatural (R) diastereoisomers of 5-formyltetrahydrofolate. In contrast to the natural isomer, which disappears rapidly from plasma, the unnatural form has a much longer half-life [12]. High concentration of the unnatural isomer can interfere with the transport and metabolism of the natural isomer. Both of the isomers can interact with TS, and inhibit its activity and thereby also the effectiveness of 5-FU chemotherapy [22].

The results of the present study showed that there was a high inter-individual variation of folates in both tumour and mucosa. This finding is in agreement with previous results published by our group [18] as well as by others [23]. Higher concentrations were found in tumour tissue compared to mucosa in all patient groups. The folate concentration increased with increasing LV dosage in both tumour and mucosa tissue. It is noteworthy that for many patients who received a dose of $60 \mathrm{mg} / \mathrm{m}^{2} \mathrm{LV}$, the resulting folate concentration in tumour tissue was as low, or even lower, than the concentration found in untreated patients. This result indicates that some patients may be unable to transport and/or metabolize LV properly. The low tissue folate concentration in some patients may also reflect an initial folate deficiency that requires a higher dosage of LV to achieve satisfying concentrations. Other results of the study points in the same direction; there was a strong and significant correlation between folate concentration in tumour and mucosa obtained from untreated patients as well as in those treated with $60 \mathrm{mg} / \mathrm{m}^{2} \mathrm{LV}$, but not between tumour and mucosa of patients treated with 200 or $500 \mathrm{mg} / \mathrm{m}^{2} \mathrm{LV}$. The lack of correlation in the latter groups may be due to faster saturation of folates in tumour tissue. Differences between patients treated with 60 versus 200 or $500 \mathrm{mg} / \mathrm{m}^{2} \mathrm{LV}$ were also reflected in plasma folates and were especially apparent when the 5-MTHF/LV ratio was compared between groups. The 5-MTHF/LV ratio might be useful as a surrogate marker for folate concentration in tumour tissue and, thus, clinically relevant.

In a previous retrospective study, the expression of 22 folate pathway genes having possible impact on the metabolism of LV was analysed in tumours deriving from 193 patients with stage III CRC treated with bolus adjuvant FLV chemotherapy [24]. The analysed genes were involved in folate transport, polyglutamation and metabolism. The result showed that high expression of two genes involved in folate transport, SLC46A1/PCFT and SLC19A1/RFC-1, correlated positively with longer disease-free survival of the patients. It was hypothesized that poor response to FLV therapy in some patients was linked to low expression of these genes. In the present study, the expression of SLC46A1/PCFT and SLC19A1/RFC-1, as well as four other folate pathway genes (ABCC3/MRP3, FPGS, GGH, and MTHFD1L) was determined.

The ABCC3/MRP3 gene encodes a protein that belongs to the superfamily of adenosine triphosphate (ATP)-binding cassette $(\mathrm{ABC})$ transporters. $\mathrm{ABCC} 3 / \mathrm{MRP} 3$ carries out an outward transport of a variety of molecules, including monoglutamated forms of reduced folates [25]. The enzyme FPGS converts folate monoglutamates to polyglutamates [26]. Polyglutamate forms of 5,10-MeTHF are better stabilizers of the ternary complex with TS and FdUMP. Studies have shown that LV is ineffective if cells are incapable of metabolizing folate to polyglutamate because the ternary complex will dissociate more readily in the absence of these polyglutamates. The enzyme 

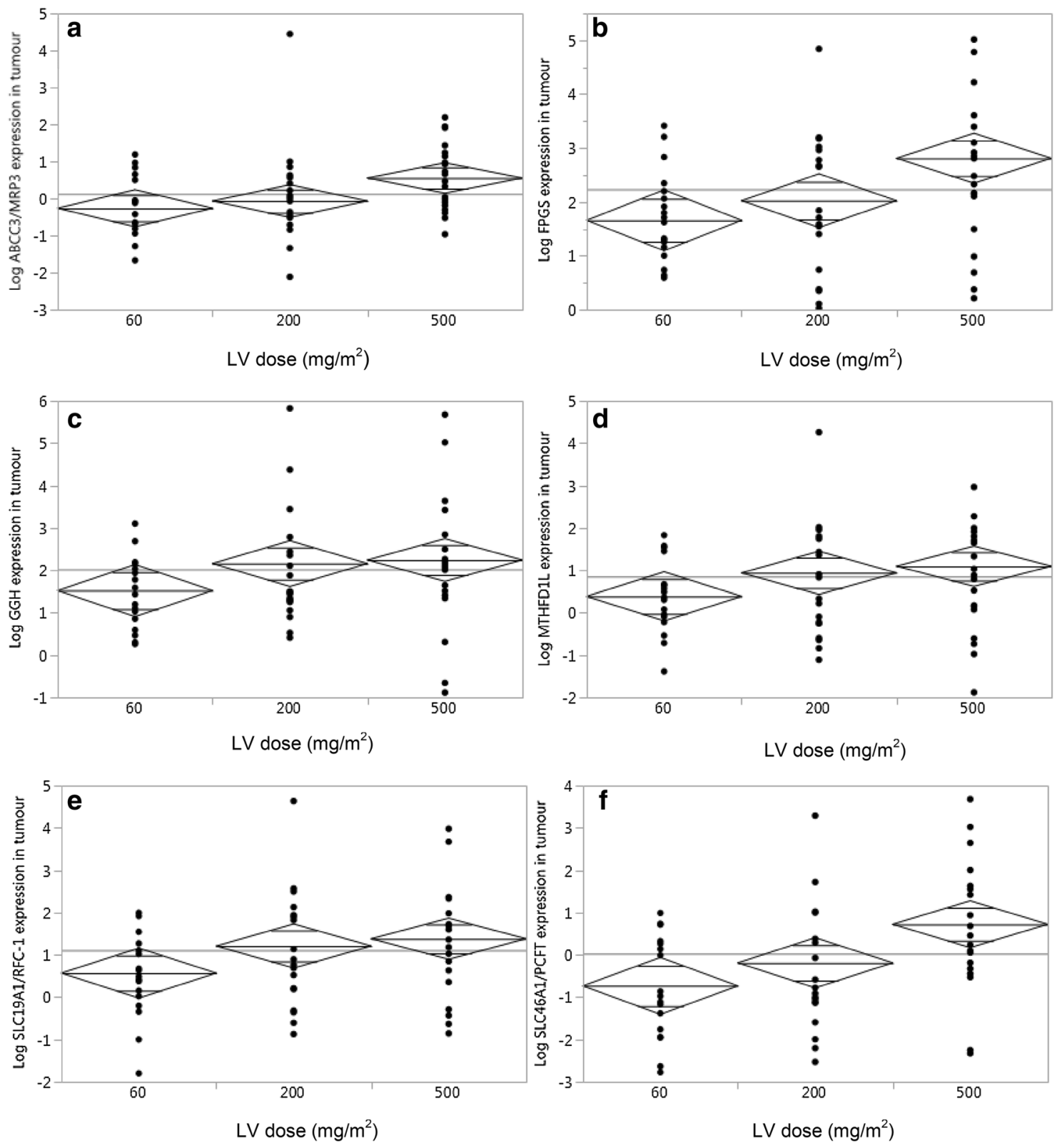

Fig. 2 Mean diamonds showing the difference in expression level of a $\operatorname{ABCC} 3 / \operatorname{MRP} 3(p=0.015)$, b FPGS $(p=0.044)$, c GGH $(p=0.05)$, d MTHFD1L $(p=0.18)$, e SLC19A1/RFC-1 $(p=0.047)$, and $\mathbf{f}$ SLC46A1/PCFT $(p=0.011)$ in tumour tissue of each group. The $\mathrm{p}$ values are based on the difference between patient groups treated with

$\mathrm{GGH}$, on the other hand, cleaves folate polyglutamates to monoglutamates [27]. It has been suggested that GGH regulates the intracellular folate concentration [28]. MTHFD1L is another gene that seems to have a critical role in folate cycle maintenance [29]. The gene encodes a mitochondrial enzyme that catalyses the conversion of 10-formylTHF to THF and formate [30]. Studies have shown that an increased level of MTHFD1L may support colorectal cancer growth [31]. the lowest and highest doses of LV, i.e. 60 and $500 \mathrm{mg} / \mathrm{m}^{2}$. As shown, the expression increased with increasing dose of LV. The horizontal line in the centre of each diamond shows the mean of each group. The top and bottom points of the diamonds show the upper and lower $95 \%$ confidence points

The results of the study showed that tumour tissue of untreated patients had higher expression of FPGS, GGH, MTHFD1L, and SLC19A1/RFC-1 compared with mucosa, whereas expression of ABCC3/MRP3 and SLC46A1/PCFT was higher in mucosa compared with tumour. These results are in agreement with those of our previous study with patients with stage III CRC, where tumour and mucosa tissue were obtained at primary surgery, before onset of adjuvant treatment [24]. Higher expression of ABCC3/MRP3 
Table 4 Pairwise correlation of gene expression and folate concentration in tissue obtained from untreated patients and patients receiving 60,200 , or $500 \mathrm{mg} / \mathrm{m}^{2}$ of $\mathrm{LV}$

\begin{tabular}{|c|c|c|c|c|c|c|c|c|}
\hline \multirow[t]{3}{*}{ Gene } & \multicolumn{4}{|c|}{ Folate concentration (no LV given) } & \multicolumn{4}{|c|}{$\begin{array}{l}\text { Folate concentration }(60,200 \text { or } 500 \mathrm{mg} \\
\mathrm{m} 2 \mathrm{LV} \text { given })\end{array}$} \\
\hline & \multicolumn{2}{|c|}{ Tumour } & \multicolumn{2}{|c|}{ Mucosa } & \multicolumn{2}{|c|}{ Tumour } & \multicolumn{2}{|l|}{ Mucosa } \\
\hline & $r^{\mathrm{a}}$ & $p^{\mathrm{b}}$ & $r^{\mathrm{a}}$ & $p^{\mathrm{b}}$ & $r^{\mathrm{a}}$ & $p^{\mathrm{b}}$ & $r^{\mathrm{a}}$ & $p^{\mathrm{b}}$ \\
\hline ABCC3/MRP3 & 0.13 & 0.6 & -0.36 & 0.14 & 0.32 & 0.018 & 0.15 & 0.28 \\
\hline FPGS & 0.32 & 0.19 & -0.38 & 0.12 & 0.31 & 0.022 & 0.22 & 0.11 \\
\hline GGH & 0.10 & 0.69 & -0.52 & 0.026 & 0.28 & 0.041 & 0.22 & 0.12 \\
\hline MTHFD1L & 0.24 & 0.35 & -0.50 & 0.033 & 0.24 & 0.078 & -0.027 & 0.85 \\
\hline SLC19A1/RFC-1 & 0.32 & 0.20 & 0.20 & 0.43 & 0.32 & 0.017 & 0.21 & 0.12 \\
\hline SLC46A1/PCFT & 0.15 & 0.56 & -0.44 & 0.071 & 0.35 & 0.0099 & 0.31 & 0.024 \\
\hline
\end{tabular}

${ }^{\mathrm{a}} r=$ correlation coefficient

${ }^{\mathrm{b}} p$ by Pearson
Table 5 Pairwise correlation of gene expression in tissue and 5-MTHF levels in plasma obtained from untreated patients

\begin{tabular}{llllll}
\hline Gene & \multicolumn{3}{l}{ 5-MTHF in plasma } & & \\
\cline { 2 - 3 } & \multicolumn{2}{l}{ Tumour } & & \multicolumn{2}{l}{ Mucosa } \\
\cline { 2 - 3 } \cline { 5 - 6 } & $r^{\mathrm{a}}$ & $p^{\mathrm{b}}$ & & $r^{\mathrm{a}}$ & $p^{\mathrm{b}}$ \\
\hline ABCC3/MRP3 & -0.12 & 0.63 & & -0.21 & 0.39 \\
FPGS & -0.37 & 0.13 & & -0.36 & 0.15 \\
GGH & -0.48 & 0.045 & -0.23 & 0.36 \\
MTHFD1L & -0.30 & 0.23 & -0.33 & 0.18 \\
SLC19A1/RFC-1 & -0.44 & 0.07 & -0.41 & 0.09 \\
SLC46A1/PCFT & -0.513 & 0.03 & -0.45 & 0.059 \\
\hline
\end{tabular}

${ }^{\mathrm{a}} r=$ correlation coefficient

${ }^{\mathrm{b}} p$ by Pearson

in mucosa compared with tumour tissue has also been reported by Kobayashi et al. at both the mRNA and protein level [32]. For each of the analysed genes, the expression in tumour increased with increasing dose of LV. Such an increase was not seen in mucosa. After LV injection, the expression of FPGS, GGH, MTHFD1L, and SLC19A1/ RFC-1 was significantly higher in tumour tissue compared to the mucosa. However, this was not the case for ABCC3/ MRP3 and SLC46A1/PCFT, which consistently had higher expression levels in mucosa, compared to tumour in each of the treatment groups.

Several previous studies have shown that folate deficiency results in a significant upregulation of folate transport genes such as SLC19A1/RFC-1 and SLC46A1/PCFT [33, 34]. Folate deficiency also results in decreased half-lives of these two genes [35]. In the present study, no correlation between gene expression and folate concentration was found in tumour tissue of untreated patients; however, the gene expression levels of GGH and SLC46A1/PCFT in tumour were negatively correlated with 5-MTHF in plasma (i.e. low folates correlated with high expression). Furthermore, high GGH and MTHFD1L expression was associated with low folate concentration in mucosa of untreated patients. This negative correlation may reflect a folate deficiency. After LV treatment, a significant positive correlation was seen between the folate concentration and expression of all genes, except MTHFD1L, in tumour tissue. However, only SLC46A1/PCFT gene expression correlated with folate concentration in mucosa. Studies have shown that the expression level of folate-associated genes in tumour tissue are different compared to mucosa. This disparity may relate to the folate status but also to differences in the regulation of folate metabolism, as has been suggested by Sadahiro et al. [36].

There are limitations of the present study. Firstly, the number of patients included in each group was limited, which may have affected the statistical calculations. However, similar results have been obtained previously in a large and unrelated study, at least at the gene expression level, which strengthens the results. Secondly, tissue was only obtained at one occasion for each of the patients. Thus, no baseline values could be compared with values after $\mathrm{LV}$ treatment at the individual level. A larger study is now being planned where samples will be obtained from each patient before and after treatment with LV in combination with 5-FU. Thirdly, the time span for sampling of plasma 5-MTHF was too short to detect the peak level of this metabolite. In the planned study, plasma samples will be obtained during a longer time span in an attempt to detect the peak concentration. Fourthly, the time to tissue sampling after LV injection differed between patients, however, as the time to injection was known, it could be adjusted for in the statistical calculations.

\section{Conclusions}

In summary, there was a high inter-individual variation in tissue and plasma folate concentration in response to administration of LV among patients. Half of the patients who received $60 \mathrm{mg} / \mathrm{m}^{2} \mathrm{LV}$ did not reach a folate concentration 
in tumour tissue above the level of untreated patients. Thus, a large part of patients with CRC may benefit from higher $\mathrm{LV}$ doses than recommended, or treatment with folate forms with different metabolic profiles. The fact that a strong correlation between mucosa and tumour tissue was found suggests that there is a possibility to use the remnant colorectal mucosa after surgery as a surrogate for tumour tissue during chemotherapy treatment. Prediction of the folate concentration in tissue before treatment with LV would be valuable in order to identify patients who would benefit from higher doses than commonly used. The results further indicate that it might be possible to use the individual response, measured as the ratio between 5-MTHF and LV concentrations in plasma after LV injection, as a surrogate marker for the folate concentration in the target tissue. In the CRC metastatic setting, the possibility to analyse a blood sample would be a useful tool for individualization of folate-based treatment. Analysis of folate-associated gene expression in tissue obtained either from primary tumours, or metastatic lesions in a palliative setting, might become useful when choosing the most optimal LV dose needed to maximize tissue concentration of 5,10-MeTHF. However, the results need to be confirmed in extended studies.

Acknowledgements We thank H. Björkqvist and A-L. Helminen for collection of surgical samples, L. Munro for work with the clinical database, and acknowledge J. Flach and M. Åkerström for technical assistance. We also thank personnel at Genomics and Bioinformatics Core Facilities for help with statistical analyses.

Funding This work was supported by grants from the Swedish Cancer Society, the King Gustav V Jubilee Clinic Foundation for Cancer Research, the Swedish state under the LUA/ALF agreement, the Anna-Lisa and Bror Björnsson Foundation, and the IngaBritt and Arne Lundberg Foundation.

\section{Compliance with ethical standards}

Conflict of interest The authors disclose no potential conflicts of interest.

Ethical approval The study was conducted in accordance with the ethical standards established in the 1964 Declaration of Helsinki and its later amendments. The study was approved by the Regional Ethics Committee in Gothenburg and all patients participating in the study provided informed consent before enrolment.

Open Access This article is distributed under the terms of the Creative Commons Attribution 4.0 International License (http://creativeco mmons.org/licenses/by/4.0/), which permits unrestricted use, distribution, and reproduction in any medium, provided you give appropriate credit to the original author(s) and the source, provide a link to the Creative Commons license, and indicate if changes were made.

\section{References}

1. Arnold M, Sierra MS, Laversanne M, Soerjomataram I, Jemal A, Bray F (2017) Global patterns and trends in colorectal cancer incidence and mortality. Gut 66(4):683-691. https://doi.org/10.1136/ gutjnl-2015-310912

2. Torre LA, Bray F, Siegel RL, Ferlay J, Lortet-Tieulent J, Jemal A (2015) Global cancer statistics, 2012. CA Cancer J Clin 65(2):87108. https://doi.org/10.3322/caac.21262

3. Van Cutsem E, Cervantes A, Adam R, Sobrero A, Van Krieken JH, Aderka D, Aranda Aguilar E, Bardelli A, Benson A, Bodoky G, Ciardiello F, D'Hoore A, Diaz-Rubio E, Douillard JY, Ducreux M, Falcone A, Grothey A, Gruenberger T, Haustermans K, Heinemann V, Hoff P, Kohne CH, Labianca R, Laurent-Puig P, Ma B, Maughan T, Muro K, Normanno N, Osterlund P, Oyen WJ, Papamichael D, Pentheroudakis G, Pfeiffer P, Price TJ, Punt C, Ricke J, Roth A, Salazar R, Scheithauer W, Schmoll HJ, Tabernero J, Taieb J, Tejpar S, Wasan H, Yoshino T, Zaanan A, Arnold D (2016) ESMO consensus guidelines for the management of patients with metastatic colorectal cancer. Ann Oncol 27(8):1386-1422. https://doi.org/10.1093/annonc/mdw235

4. Sorbye H, Pfeiffer P, Cavalli-Bjorkman N, Qvortrup C, Holsen MH, Wentzel-Larsen T, Glimelius B (2009) Clinical trial enrollment, patient characteristics, and survival differences in prospectively registered metastatic colorectal cancer patients. Cancer 115(20):4679-4687. https://doi.org/10.1002/cncr.24527

5. Andre T, Boni C, Navarro M, Tabernero J, Hickish T, Topham C, Bonetti A, Clingan P, Bridgewater J, Rivera F, de Gramont A (2009) Improved overall survival with oxaliplatin, fluorouracil, and leucovorin as adjuvant treatment in stage II or III colon cancer in the MOSAIC trial. J Clin Oncol 27(19):3109-3116. https://doi. org/10.1200/jco.2008.20.6771

6. Sargent D, Sobrero A, Grothey A, O'Connell MJ, Buyse M, Andre T, Zheng Y, Green E, Labianca R, O'Callaghan C, Seitz JF, Francini G, Haller D, Yothers G, Goldberg R, de Gramont A (2009) Evidence for cure by adjuvant therapy in colon cancer: observations based on individual patient data from 20,898 patients on 18 randomized trials. J Clin Oncol 27(6):872-877. https://doi. org/10.1200/jco.2008.19.5362

7. Wolmark N, Rockette H, Fisher B, Wickerham DL, Redmond C, Fisher ER, Jones J, Mamounas EP, Ore L, Petrelli NJ et al (1993) The benefit of leucovorin-modulated fluorouracil as postoperative adjuvant therapy for primary colon cancer: results from National Surgical Adjuvant Breast and Bowel Project protocol C-03. J Clin Oncol 11(10):1879-1887

8. Wilson PM, Danenberg PV, Johnston PG, Lenz HJ, Ladner RD (2014) Standing the test of time: targeting thymidylate biosynthesis in cancer therapy. Nat Rev Clin Oncol 11(5):282-298. https:// doi.org/10.1038/nrclinonc.2014.51

9. Parker WB, Cheng YC (1990) Metabolism and mechanism of action of 5-fluorouracil. Pharmacol Ther 48(3):381-395

10. Longley DB, Latif T, Boyer J, Allen WL, Maxwell PJ, Johnston PG (2003) The interaction of thymidylate synthase expression with $\mathrm{p} 53$-regulated signaling pathways in tumor cells. Sem Oncol 30(3 Suppl 6):3-9

11. Thirion P, Michiels S, Pignon JP, Buyse M, Braud AC, Carlson RW, O'Connell M, Sargent P, Piedbois P (2004) Modulation of fluorouracil by leucovorin in patients with advanced colorectal cancer: an updated meta-analysis. J Clin Oncol 22(18):37663775. https://doi.org/10.1200/jco.2004.03.104

12. Houghton JA, Williams LG, de Graaf SS, Cheshire PJ, Rodman JH, Maneval DC, Wainer IW, Jadaud P, Houghton PJ (1990) Relationship between dose rate of [6RS]Leucovorin administration, plasma concentrations of reduced folates, and pools of 
5,10-methylenetetrahydrofolates and tetrahydrofolates in human colon adenocarcinoma xenografts. Cancer Res 50(12):3493-3502

13. Glimelius B, Jakobsen A, Graf W, Berglund A, Gadeberg C, Hansen P, Kjaer M, Brunsgaard N, Sandberg E, Lindberg B, Sellstrom H, Lorentz T, Pahlman L, Gustavsson B (1998) Bolus injection (2-4 min) versus short-term (10-20 min) infusion of 5-fluorouracil in patients with advanced colorectal cancer: a prospective randomised trial. Nordic Gastrointestinal Tumour Adjuvant Therapy Group. Eur J Cancer (Oxf Engl 1990) 34(5):674-678

14. Danenberg PV, Gustavsson B, Johnston P, Lindberg P, Moser R, Odin E, Peters GJ, Petrelli N (2016) Folates as adjuvants to anticancer agents: Chemical rationale and mechanism of action. Crit Rev Oncol Hematol 106:118-131. https://doi.org/10.1016/j.critr evonc.2016.08.001

15. Priest DG, Schmitz JC, Bunni MA, Stuart RK (1991) Pharmacokinetics of leucovorin metabolites in human plasma as a function of dose administered orally and intravenously. J Natl Cancer Inst 83(24):1806-1812

16. Lockshin A, Danenberg PV (1981) Biochemical factors affecting the tightness of 5-fluorodeoxyuridylate binding to human thymidylate synthetase. Biochem Pharmacol 30(3):247-257

17. Spears CP, Carlsson G, Muggia FM, Jaresko G, Gustavsson BG (1995) Aspects of one-carbon folate cycling related to fluoropyrimidine and antifolate therapy. Cancer Treat Res 78:115-134

18. Taflin H, Wettergren Y, Odin E, Derwinger K (2014) Folate levels measured by LC-MS/MS in patients with colorectal cancer treated with different leucovorin dosages. Cancer Chemother Pharmacol 74(6):1167-1174. https://doi.org/10.1007/s00280-014-2591-9

19. Houghton JA, Williams LG, Loftin SK, Cheshire PJ, Morton CL, Houghton PJ, Dayan A, Jolivet J (1992) Factors that influence the therapeutic activity of 5-fluorouracil [6RS]leucovorin combinations in colon adenocarcinoma xenografts. Cancer Chemother Pharmacol 30(6):423-432

20. Odin E, Wettergren Y, Carlsson G, Gustavsson B (2013) Determination of reduced folates in tumor and adjacent mucosa of colorectal cancer patients using LC-MS/MS. Biomed Chromatogr BMC 27 (4):487-495. https://doi.org/10.1002/bmc.2816

21. Jensen NF, Smith DH, Nygard SB, Romer MU, Nielsen KV, Brunner N (2012) Predictive biomarkers with potential of converting conventional chemotherapy to targeted therapy in patients with metastatic colorectal cancer. Scand J Gastroenterol 47(3):340 355. https://doi.org/10.3109/00365521.2012.640835

22. Lee PP, Schilsky RL (1990) Inhibition of thymidylate synthase by the diastereoisomers of leucovorin. Cancer Chemother Pharmacol 26(4):273-277

23. Schlemmer M, Kuehl M, Schalhorn A, Rauch J, Jauch KW, Hentrich M (2008) Tissue levels of reduced folates in patients with colorectal carcinoma after infusion of folinic acid at various dose levels. Clin Cancer Res 14(23):7930-7934. https://doi. org/10.1158/1078-0432.ccr-08-0258

24. Odin E, Sonden A, Gustavsson B, Carlsson G, Wettergren Y (2015) Expression of folate pathway genes in stage III colorectal cancer correlates with recurrence status following adjuvant bolus 5-FU-based chemotherapy. Mol Med (Camb Mass) 21:597-604. https://doi.org/10.2119/molmed.2014.00192

25. Hooijberg JH, Peters GJ, Assaraf YG, Kathmann I, Priest DG, Bunni MA, Veerman AJ, Scheffer GL, Kaspers GJ, Jansen G
(2003) The role of multidrug resistance proteins MRP1, MRP2 and MRP3 in cellular folate homeostasis. Biochem Pharmacol 65(5):765-771

26. Lowe KE, Osborne CB, Lin BF, Kim JS, Hsu JC, Shane B (1993) Regulation of folate and one-carbon metabolism in mammalian cells. II. Effect of folylpoly-gamma-glutamate synthetase substrate specificity and level on folate metabolism and folylpoly-gammaglutamate specificity of metabolic cycles of one-carbon metabolism. J Biol Chem 268(29):21665-21673

27. Galivan J, Ryan TJ, Chave K, Rhee M, Yao R, Yin D (2000) Glutamyl hydrolase. pharmacological role and enzymatic characterization. Pharmacol Ther 85(3):207-215

28. Kawakami K, Ooyama A, Ruszkiewicz A, Jin M, Watanabe G, Moore J, Oka T, Iacopetta B, Minamoto T (2008) Low expression of gamma-glutamyl hydrolase mRNA in primary colorectal cancer with the $\mathrm{CpG}$ island methylator phenotype. $\mathrm{Br} \mathrm{J}$ Cancer 98(9):1555-1561. https://doi.org/10.1038/sj.bjc.6604346

29. Lee D, Xu IM, Chiu DK, Lai RK, Tse AP, Lan Li L, Law CT, Tsang FH, Wei LL, Chan CY, Wong CM, Ng IO, Wong CC (2017) Folate cycle enzyme MTHFD1L confers metabolic advantages in hepatocellular carcinoma. J Clin Investig 127(5):1856-1872. https ://doi.org/10.1172/jci90253

30. Pike ST, Rajendra R, Artzt K, Appling DR (2010) Mitochondrial C1-tetrahydrofolate synthase (MTHFD1L) supports the flow of mitochondrial one-carbon units into the methyl cycle in embryos. J Biol Chem 285(7):4612-4620. https://doi.org/10.1074/jbc. M109.079855

31. Lee D, Wong CC (2017) The folate cycle is a new metabolic weakness of cancer. Mol Cell Oncol 4(6):e1327004. https://doi. org/10.1080/23723556.2017.1327004

32. Kobayashi M, Funayama R, Ohnuma S, Unno M, Nakayama K (2016) Wnt-beta-catenin signaling regulates ABCC3 (MRP3) transporter expression in colorectal cancer. Cancer Sci 107(12):1776-1784. https://doi.org/10.1111/cas.13097

33. Thakur S, Kaur J (2015) Regulation at multiple levels control the expression of folate transporters in liver cells in conditions of ethanol exposure and folate deficiency. BioFactors 41(4):232-241. https://doi.org/10.1002/biof.1217

34. Crott JW, Liu Z, Keyes MK, Choi SW, Jang H, Moyer MP, Mason JB (2008) Moderate folate depletion modulates the expression of selected genes involved in cell cycle, intracellular signaling and folate uptake in human colonic epithelial cell lines. $\mathbf{J}$ Nutr Biochem 19(5):328-335. https://doi.org/10.1016/j.jnutb io.2007.05.003

35. Thakur S, More D, Rahat B, Khanduja KL, Kaur J (2016) Increased synthesis of folate transporters regulates folate transport in conditions of ethanol exposure and folate deficiency. Mol Cell Biochem 411(1-2):151-160. https://doi.org/10.1007/s1101 0-015-2577-x

36. Sadahiro S, Suzuki T, Maeda Y, Tanaka A, Ogoshi K, Kamijo A, Murayama C, Tsukioka S, Sakamoto E, Fukui Y, Oka T (2010) Molecular determinants of folate levels after leucovorin administration in colorectal cancer. Cancer Chemother Pharmacol 65(4):735-742. https://doi.org/10.1007/s00280-009-1079-5 